\title{
A INFLUENCIA DO DESEÑO EXTERIOR DO ESTABLECEMENTO COMERCIAL NA “VENDA LIBRE" DA OFICINA DE FARMACIA
}

Fernando Losada Pérez Facultade de Administración e Dirección de Empresas, Avda. Alfonso X el Sabio s/ n, 27002

LUGOE-mail: fernando.losada@usc.es

Santiago Torres Labandeira

Avda. de la Coruña, 299, 27003 LUGO E-mail: santiagotorres@redfarma.org

\section{Resumo:}

Os cambios que se produciron no sector das oficinas de farmacia reduciron sensiblemente os ingresos e os beneficios obtidos coa venda de medicamentos con receita. Isto obrigou aos farmacéuticos a cambiar a forma de xestionar o seu negocio, baseada en "despachar" menciñas, para adoptar unha actitude máis activa fundamentada na aplicación das técnicas de merchandising co obxectivo de incrementar a venda libre (produtos de parafarmacia e especialidades farmacéuticas publicitarias), e depender menos dos medicamentos con receita.

Nesta investigación analízase a importancia que dentro destas técnicas comerciais, desempeña o deseño exterior do punto de venda como estratexia que anima aos potenciais clientes a entrar no establecemento comercial, e polo tanto aumentar a posibilidade de que os consumidores adquiran os produtos incluídos na carteira de produtos da farmacia. En particular, analízase a influencia que a fachada, os letreiros, a cruz, a porta de entrada e o escaparate teñen na venda libre da farmacia.

Palabras chave: farmacia, deseño exterior, fachada, letreiros, cruz, porta de entrada, escaparate, venda libre.

THE INFLUENCE OF THE COMMERCIAL ESTABLISHMENT'S DESIGN OUTDOORS IN THE SALES OF A PHARMACY'S OVER-THE-COUNTER DRUGS

\section{Abstract:}

Due to the changes in the pharmaceutical industry, the revenues and profits from the sale of prescription drugs have been significantly reduced. That is why pharmacists have to change the way in which they run their business, based on dispensing prescription drugs, in order to adopt a more active attitude based on the application of merchandising techniques in order to increase the sales of over-the-counter drugs (parapharmaceutical products and advertising pharmaceutical specialties), so they are able to be less dependent on the prescription drugs. This study analyzes the importance of outdoor design as a strategy to encourage potential customers to go inside the commercial establishment; and thus increase the possibility for consumers to purchase the products included in the pharmacy product portfolio. In particular, the influence of the façade, the pharmacy sign, the pharmacy cross, the front door and the shop window, on the sales of over-the-counter drugs of the pharmacy is analyzed.

Keywords: pharmacy, exterior design, façade, pharmacy sign, pharmacy cross, front door, shop window, over-the-counter drugs.

\section{Introdución}

A oficina de farmacia é unha empresa cunhas características moi singulares das que destaca a elevada lexislación que regula o sector no que se atopa. O propietario dunha farmacia debe ser consciente de que as medidas de control do gasto farmacéutico que se produciu nos últimos anos, consecuencia dos cambios lexislativos promovidos polos diferentes gobernos estatais e autonómicos, minguaron significativamente os ingresos e os beneficios obtidos, ata tal punto que en ocasións se fai inviable o desenvolvemento da actividade. 
Neste contexto, é fundamental para o farmacéutico entender e aplicar as modernas técnicas de xestión do punto de venda encamiñadas cara a captación de novos clientes e a retención dos consumidores actuais. O obxectivo para a oficina de farmacia é procurar facerse menos dependente das menciñas con receita e ampliar a súa facturación en produtos de parafarmacia e especialidades farmacéuticas publicitarias (EFP). Para iso, o deseño da estratexia comercial do punto de venda débese basear nunha serie de técnicas comerciais incluídas baixo o nome de merchandising.

Dentro do merchandising, o deseño exterior do establecemento comercial convértese nun factor fundamental xa que permite poñer de manifesto a verdadeira identidade e a personalidade do punto de venda, contribuíndo deste xeito a reforzar o seu posicionamento e a atracción dos clientes ao punto de venda (Díez e Landa, 1996). Ademais, facilita a identificación do establecemento comercial e constitúe un elemento fundamental á hora de transmitir a súa imaxe corporativa que se exterioriza a nivel físico e psicolóxico (Palomares, 2009).

Neste senso, o obxectivo que se quere acadar con este traballo de investigación é analizar a influencia que o deseño exterior da oficina de farmacia exerce sobre a venda libre (produtos de parafarmacia e EFP), coa finalidade de compensar a perda de facturación obtida a través dos medicamentos con receita e facer á farmacia moito máis competitiva e adaptada aos cambios da contorna.

Para acadar o obxectivo proposto seguiuse a seguinte estrutura. En primeiro lugar, analízase de forma resumida a situación actual das oficinas de farmacia en España. Na segunda parte do traballo expóñense os principais aspectos relacionados co deseño exterior da farmacia: a fachada, os letreiros, a cruz, as portas de entrada e o escaparate. A continuación, desenvólvese o estudo empírico realizado e preséntanse os resultados obtidos. Finalmente, expóñense as conclusións máis importantes que se poden extraer dos resultados obtidos, as implicacións e recomendacións para a xestión, así como as limitacións do estudo e as futuras liñas de investigación.

\section{Situación das oficinas de farmacia en España}

As oficinas de farmacia son establecementos sanitarios privados de interese público, suxeitos á planificación sanitaria que establezan as Comunidades Autónomas. O farmacéutico titular-propietario da mesma, asistido, no seu caso, de axudantes ou auxiliares, deberá prestar diferentes servizos básicos á poboación en canto a medicamentos e produtos sanitarios contidos na Lei 16/1997, do 25 de abril, de regulación de servizos das Oficinas de Farmacia.

$\mathrm{Na}$ actualidade, a función do profesional farmacéutico dinamizouse, implicándose máis na atención integral da saúde ou do benestar da poboación. Neste senso, a farmacia en España evolucionou nos últimos anos cara unha farmacia de servizos, moito máis achegada ao cidadán. Esta evolución non é realizable sen un simultáneo exercicio comercial a través do cal se obteña a troco unha ganancia ou beneficio económico, como calquera outra empresa, o que xerou unha maior competencia entre as mesmas farmacias e outros establecementos que ofrecen produtos semellantes (agás medicamentos).

A oficina de farmacia na actualidade sufre un alto nivel de intervención por parte do Sistema Nacional de Saúde, con constantes cambios lexislativos que están poñendo en dúbida a sostibilidade do modelo actual.

Os recortes das marxes de beneficio, a lexislación restritiva, a caída dos prezos dos medicamentos, a chegada doutros competidores no campo da parafarmacia, o copago e a receita electrónica, unido aos aprazamentos de pago da Seguridade Social e as correntes liberalizadoras do sector que veñen de Europa, cuestionan que a calidade asistencial prestada ata o de agora pola oficina de farmacia sexa sostible. 
Neste senso, as farmacias teñen que asumir, se queren seguir sendo competitivas e rendibles, un cambio de actitude na forma de xestionar tradicionalmente o negocio, no que os farmacéuticos deben deixar de "despachar" e pasar a dispensar produtos distintos aos medicamentos, que ata a actualidade constituían o piar da súa actividade comercial. É dicir, adoptar unha actitude máis proactiva en relación coas vendas, e, en particular, a incrementar a facturación de produtos de venda libre (produtos de parafarmacia e EFP). Nesta dirección, De la Fuente (2017) sinala que é responsabilidade de todos os profesionais manter unha actitude proactiva e continuar innovando coa intención de sortear os posibles obstáculos que poidan afectar á farmacia no eido lexislativo, comercial, de competencia ou de cambios de compra dos clientes.

O papel do farmacéutico como xestor cambiou, xa non chega con dispensar unha receita, agora a satisfacción do cliente require desenvolver unha gran variedade de accións como parte da estratexia de márketing, procurando satisfacelo e detectar as súas necesidades futuras (De la Fuente, 2016).

\section{Deseño exterior da oficina de farmacia}

Conforme a Zorrilla (2002), o deseño exterior dun establecemento comercial constitúe unha fonte de información que xera unha primeira impresión, máis importante canto maior descoñecemento teña a clientela sobre o establecemento e inflúe moi directamente na decisión de entrar ou non.

No sector das farmacias, González (2008a) sinala que o deseño exterior do punto de venda permite marcar a súa identidade, é dicir, a súa verdadeira personalidade e o seu estilo, así como a do persoal que traballa nela e a do seu titular.

Tendo en conta a importancia que o deseño exterior do punto de venda ten dende o punto de vista da imaxe comercial que se quere transmitir e na atracción dos clientes potenciais ao establecemento comercial, este debe conseguir os seguintes obxectivos (Martínez, 2005; Díez, Landa e Navarro, 2006; Siles, 2012):

- Transmitir a imaxe corporativa do establecemento comercial e dos produtos que comercializa.

- Posicionar o establecemento na mente do consumidor segundo un estilo e personalidade definidos.

- Facilitar a visualización do establecemento comercial, destacándoo e diferenciándoo fronte ao resto de establecementos competidores.

- Identificar e localizar o punto de venda de forma fácil para os clientes que veñan á procura do establecemento por primeira vez.

- Captar a atención dos clientes potenciais a través dun deseño atractivo do exterior do punto de venda.

- Incitar a acción de entrar no establecemento comercial e provocar accións de compra. Conseguir a máxima visibilidade e identificación da farmacia dependerá dos sistemas de comunicación exterior que se empreguen, o feito de que un consumidor se interese pola oferta e que entren vai ser o resultado do escaparate e a imaxe proxectada dende 0 exterior e o que merquen dependerá ademais, da correcta disposición interior do punto de venda, así como da conduta do persoal de contacto. A imaxe corporativa externa da farmacia é chave para gañar a credibilidade no interior, diferenciarse do resto de competidores e definir o posicionamento da oficina de farmacia (Dermoactiva, 2009).

Dentro do deseño exterior do punto de venda, a meirande parte dos investigadores consideran catro piares básicos sobre os que se proxecta a imaxe exterior de calquera establecemento comercial: a fachada, os letreiros, a porta de entrada ou acceso ao 
establecemento e o escaparate. Ademais, nas farmacias distínguese un quinto elemento cuxa utilización é preceptiva: a cruz.

Estes cinco elementos son os que analizaremos a continuación.

\subsection{A Fachada}

A fachada ten como obxectivo fundamental que os individuos perciban con claridade a actividade que se desenvolve no establecemento comercial (Martínez, 2005). Constitúe a primeira imaxe da farmacia e a que xera a primeira impresión dos clientes, é a carta de presentación do establecemento (González, 2008a).

Os elementos que forman parte do exterior da mesma configuran unha parte da marca da farmacia onde se ve reflectida a identidade e a personalidade da mesma. O obxectivo principal é captar a atención do viandante e invitalo a entrar na mesma, debe transmitir a identidade interior no exterior.

Conforme a Brocal e Vaillo (2005), captar a atención dos clientes debe empezar por unha fachada que permita unha fácil localización da farmacia. Para iso, é importante coidar os distintos elementos que poidan axudar á súa perfecta localización e que sirvan de preludio ao que, posteriormente, o cliente poderá albiscar no escaparate. Estes autores consideran que para acadar este obxectivo as farmacias deberían ter en conta os seguintes elementos: a cruz, a placa identificativa do farmacéutico titular, os letreiros identificativos da farmacia, a porta de acceso, así como outros indicadores como paneis indicadores das farmacias que están de garda ou as farmacias máis próximas.

Coforme a González (2012), a imaxe da fachada da farmacia debe ser limpa e harmoniosa, é o primeiro contacto co establecemento, e debe coidar a transparencia e o equilibrio.

Por outra banda, dende o punto de vista de animación do punto de venda, a fachada debe conseguir os seguintes obxectivos (González, 2008a):

- Ser un fiel reflexo da identidade e política comercial da farmacia.

- Permitir ver o interior do punto de venda mediante amplos escaparates, portas acristaladas, etc.

- Manter unha limpeza impecable.

- Ter que estar ben iluminada, cunha luz que realce a entrada e os escaparates e facilite en todo momento a visión dos lineais.

- Dispor dun letreiro e logotipo (se o ten) ben visible, xa que son elementos que forman parte da diferenciación do establecemento.

- $\quad$ Dispor dun panel no que se reflexen os diferentes servizos de que dispón a farmacia: dietas personalizadas, diagnósticos de pel e cabelo, control de parámetros de saúde...

- Incluír información sobre promocións e ofertas, así como das campañas existentes.

Conforme a Díez, Landa e Navarro (2006) nunha fachada pódense distinguir dous niveis: a parte superior, que cumpre unha misión de localización e identificación, e a parte inferior, que ten como misión atraer aos viandantes.

Na farmacia o nivel superior cumpre a misión de localización e inclúe o letreiro e a cruz e ten como función que o transeúnte identifique a farmacia dende lonxe. O nivel inferior da fachada está condicionado pola propia estrutura e inclúe o escaparte e a porta que ten como función atraer, informar e incitar a entrar o cliente.

Estes elementos serán analizados a continuación.

\subsection{Os letreiros}

Os letreiros constitúen un elemento de identificación do establecemento. No seu deseño interveñen o logotipo, o tipo de letra, tamaño, cor, se é luminoso ou non de forma intermitente ou permanente e a forma horizontal ou vertical e, recoméndase que sexa visible tanto na entrada da tenda como a certa distancia (Siles, 2012).

Nunha farmacia o deseño do letreiro e do logotipo deberá realizarse conforme á imaxe que se desexe proxectar, de modo que resulte un elemento identificativo que individualice 
á farmacia con respecto á competencia e, polo tanto, que a diferencie das outras (González, 2008a).

Hai dúas cores que idenfican á farmacia: verde e branco, grazas á insistencia na utilización delas ao longo da súa historia, renunciar a este patrimonio é perder credibilidade de cara ao cliente. Este activo debe ser aproveitado polo farmacéutico, xa que é a maior garantía de cara ao cliente potencial dos servizos que lle pode proporcionar.

$\mathrm{Na}$ oficina de farmacia o letreiro coa palabra "farmacia", igual cá cruz, é obrigatorio, e sitúase sobre o frontal superior da fachada. O tamaño das letras debe ser claro e grande abondo para permitir unha lectura nítida e clara no campo visual situado diante da farmacia para permitir a súa identificación (González, 2005, 2010). Agora ben, no deseño do letreiro da farmacia débese ter en conta que se trata dun establecemento sanitario e como tal, debe transmitir unha imaxe de seriedade que concorde cos produtos e servizos que se comercializan.

Ademais, González (2012) indica que no letreiro da oficina de farmacia pódense incluír outros elementos como:

- A imaxe corporativa da farmacia que a vai diferenciar doutras farmacias.

- Directorio de servizos, elemento fundamental que vai informar ao cliente de toda a gama de solucións e servizos que pode haber na oficina de farmacia.

- Slogan, frase que reúne a filosofía estratéxica da farmacia e que lle transmite ao cliente un valor engadido diferenciado do resto de farmacias.

\subsection{A cruz}

É o indicador de referencia de localización da oficina de farmacia por parte dos consumidores. Ademais do feito de que o seu uso é preceptivo como signo identificativo dunha oficina de farmacia, é un importante instrumento de comunicación, polo que canto máis visible sexa, máis posibilidade existe que sexa percibida polos clientes potenciais, asociándoa inmediatamente á existencia dunha farmacia.

Existe unha gran variedade de modelos de cruz que ofrecen moitas posibilidades en canto a luminosidade, cores, capacidade para incorporar unha mensaxe (hora, temperatura, etc.). A pesar da gran variedade de modelos predominan as cruces gregas (o $90 \%$ de todas as farmacias) e tamén as cruces de malta (Brocal e Vaillo, 2005).

Conforme a González (2008b), na actualidade utilízanse cada vez máis cruces máis modernas, elegantes e dun grande impacto visual, cunha combinación de formas e cores exclusivas, realzando a imaxe da farmacia asemade que decorando a contorna urbana. $\mathrm{O}$ seu movemento continuo capta a atención do viandante e son igualmente visibles de día e de noite, malia que, como indican Brocal e Vaillo (2005), non convén que as luces luminosas estean encendidas durante a noite se a farmacia non está aberta, xa que poden confundir ao consumidor e xerar unha mala imaxe.

A cruz cobre dous obxectivos na súa colocación, por unha banda, rompe a linealidade dos letreiros nunha zona comercial, e, por outra, permite unha visión frontal moi rápida que identifica a localización da farmacia. Porén, a intermitencia potencia moito máis a súa percepción debido á molestia que causa no cerebro o pestanexo da luz (Dermoactiva, 2009).

Hai que destacar que a cruz tamén é un elemento que é susceptible de ser lexislado. No caso da Comunidade Autónoma de Galicia, o Decreto 107/2008, fai alusión á cruz das oficinas de farmacia: Con obxecto de facilitarlles ás usuarias e usuarios a identificación das oficinas de farmacia, deberán contar na súa fachada cunha cruz verde, cun tamaño máximo de $90 \mathrm{~cm}$ x $90 \mathrm{~cm}$, cun dispositivo que permita a súa iluminación na que deberá figurar a palabra farmacia ou botica, segundo o caso. Ademais, este Decreto sinala que durante o horario de funcionamento da oficina de farmacia deberán ter iluminada a cruz, e fóra do devandito horario a cruz deberá estar apagada. Finalmente, tamén indica que se 
poderán instalar tantas cruces como número de fachadas teña o establecemento, cando este teña abertura a diferentes rúas. Deste xeito, o farmacéutico titular debe contemplar a lexislación aplicable a nivel estatal e a que emana de cada Comunidade Autónoma e Concello onde desenvolve a súa actividade profesional.

Na actualidade, cada vez son máis as farmacias que utilizan a cruz como elemento de comunicación e diferenciación dos seus competidores directos, para iso inclúen elementos de información como a temperatura, a hora e mesmo como mensaxe publicitaria, e con iluminación led capaz de emitir mensaxes e realizar efectos chamativos a dobre cara. Polo tanto, e tendo en conta as limitacións legais, o titular da oficina de farmacia dispón dunha gran variedade de alternativas para o deseño da cruz que debe considerar en función da imaxe que se quere transmitir ao público obxectivo.

\subsection{A porta de entrada}

A decisión sobre o deseño e a localización da entrada ao punto de venda é moi importante, xa que constitúen o elemento físico que separa ao cliente do interior do establecemento e, revélase como un factor fundamental para o éxito comercial, pois incide na predisposición á compra dos clientes e no percorrido que eles realizan no punto de venda (Martínez, 2005; Díez, Landa e Navarro, 2006).

A porta nunha oficina de farmacia debe potenciar a facilidade de acceso de tal xeito que convide a entrar e non sexa unha barreira. O seu número depende das dimensións do local comercial, malia que o ideal é que só exista unha porta ampla e de fácil acceso.

É fundamental evitar as barreiras arquitectónicas que dificulten o acceso á farmacia, mellorar os accesos de entrada, para o que se poden empregar sistemas modernos de abertura de portas: cortinas de ar ou portas automáticas que faciliten o paso ao interior a persoas con carriños de bebé, imposibilitados en cadeira de rodas, etc.

A porta de entrada debe dar unha imaxe de modernidade e transmitir a idea de ser un establecemento orientado ao cliente. Ademais, débese integrar nun conxunto coherente que proxecte a imaxe que se desexe transmitir e ser un fiel reflexo do interior.

Neste senso, Brocal et al. (2007) sinalan, con vistas a acadar estes obxectivos, que a meirande parte das farmacias de novo deseño inclínanse pola instalación de portas automáticas transparentes, xa que combinan á perfección a funcionalidade coa estética, e, ao mesmo tempo, permiten unha maior accesibilidade ao punto de venda e permiten ao cliente observar o interior da farmacia dende a rúa.

Conforme a González (2008a), a porta de entrada a unha oficina de farmacia debería cumprir os seguintes requisitos:

- Ser atractiva, o máis ancha posible, evitando calquera tipo de obstáculo. O máis aconsellable é que a entrada da farmacia sexa moi ancha á rúa e estreite o paso cara 0 interior.

- Debe provocar a sensación de "porta aberta". As mellores portas son as de vidro, que permiten ver o interior da farmacia e de abertura automática.

- Débese deseñar facilitando o acceso ao interior a calquera tipo de clientes: anciáns, nais ou pais con carros de bebés, persoas co carro da compra... Neste senso, débese ter en conta que conforme o Consello Xeral de Colexios Oficiais de Farmacéuticos (2013), un terzo dos usuarios de farmacias teñen algún tipo de limitación de acceso.

- Estar situada no extremo dereito da fachada, tendo en conta a tendencia natural dos consumidores a circular no senso contrario ás agullas do reloxo.

- Deberá contar cunha iluminación axeitada que facilite a visión da identidade da oficina de farmacia.

\subsection{O escaparate}

O escaparate é o principal vehículo de comunicación entre o establecemento comercial e a súa clientela potencial, sintetizando e reflectindo o estilo da tenda, o que é e o que vende. 
Está considerado como o mellor vendedor xa que posúe un carácter eminentemente persuasivo (Palomares, 2009).

Pódese afirmar a existencia de consenso entre os investigadores en considerar o escaparate como un poderoso instrumento de comunicación ao servizo do comercio minorista, que transmite información sobre o tipo de produtos que o cliente atopará no punto de venda, actuando como un instrumento de persuasión cara o consumidor e, constituíndo unha ferramenta que forma parte da estratexia comercial da empresa e de animación do punto de venda.

Nas farmacias, ao se caracterizaren xeralmente por seren pequenos establecementos cuxas actividades de comunicación son moi limitadas, os escaparates pasan a ser unha ferramenta imprescindible de transmisión de información e persuasión cara a compra. Porén, a utilización do escaparate na oficina de farmacia como instrumento de comunicación e de animación do punto de venda, non se viu reflectida ata épocas moi recentes.

Nesa dirección, Gasulla (2008) sinala que os escaparates deixaron de ser un lugar esquecido polo farmacéutico para adquirir aos poucos a importancia que a día de hoxe teñen segundo a nova tendencia da farmacia. Este salto cualitativo foi liderado normalmente polos provedores (laboratorios), que son os que espertaron no farmacéutico a inquietude polo escaparate.

Conforme a García (2008), o escaparate é o vehículo fundamental de comunicación entre a farmacia e os seus clientes potenciais: sintetiza e reflicte o seu estilo. Un bo escaparate transmite unha imaxe clara dos produtos que se venden e posicionan á farmacia no mercado a través de elementos como o prezo, as marcas que se comercializan, a cantidade de produtos expostos e os servizos ofertados. Ademais, conséguese espertar suficiente atención e interese, provoca moitas compras impulsivas e é un instrumento moi valioso de promoción. Polo tanto, un fin primordial do escaparate é vender máis.

De maneira semellante Arias (2012) sinala que o escaparate é un elemento básico de comunicación entre a farmacia e o consumidor. Os impactos que reciben os posibles clientes non só son repetitivos e captan a súa atención, senón que poden provocar un cambio de actitude e inducir á compra.

Para cumprir cos obxectivos sinalados anteriormente, os escaparates das oficinas de farmacia deberían cumprir cunha serie de requisitos (Brocal e Vaillo, 2005; García, 2008; Dermoactiva, 2009):

- Transmisión de información. Debe reflectir o ambiente, o tipo de produto ofertado, o prezo e o posicionamento da oficina de farmacia.

- $\quad$ Orixinalidade. É importante deseñar escaparates non convencionais e diferentes aos propostos polos competidores.

- Transparencia. Convén que o escaparate teña unha parte libre que permita ver o interior da farmacia, malia que tamén se poden deseñar con fondos atractivos.

- Atracción do público obxectivo. Os temas e escenografías escollidas para decorar o escaparate deben estar adaptados ao público obxectivo ao que se dirixe a farmacia.

- Renovación. Os escaparates débense planificar e cambiar con certa periodicidade, do contrario acaban sendo aburridos e rutineiros. De media, recoméndase o seu cambio cada 15 días, pois a partir deste prazo comeza a perder efectividade. Porén, debido a que a compra é menos impulsiva que noutros sectores ${ }^{1}$, poderíase manter ata 21 días.

${ }^{1}$ Segundo García (2008) o escaparate é a zona máis promocional da farmacia e á que se deben máis do $50 \%$ das compras por impulso. 
- Correcta colocación dos produtos. O escaparate debe comunicar unha mensaxe clara e sinxela e para iso é imprescindible que non xere confusión a través da colocación dunha gran cantidade de produtos. Ademais, deben estar correctamente ordenados.

- As zonas laterais. Se o escaparate é un espazo restrinxido na fachada, os laterais débense utilizar como captadores de atención.

- $\quad$ Altura. Para unha maior visibilidade do escaparate convén que este se eleve do solo a unha distancia razoable, como mínimo $50 \mathrm{~cm}$.

- Limpeza. O escaparate é o primeiro impacto ao que está exposto o cliente con respecto á farmacia e a súa oferta real, por esta razón débese coidar especialmente a limpeza do mesmo.

- A iluminación. Debe ser axeitada ao produto exposto, para o que se aconsella dispor dun sistema de luces con focos de luz puntual e focos de luz ambiental ou dispersa independentes.

- A cor. É o elemento do escaparate con maior capacidade de estimulación sensorial e carga simbólica, pero moi difícil de empregar xa que as sensacións que transmite son moi subxectivas. Débese procurar a combinación de cores máis axeitada atendendo ao tipo de produtos que se expoñen no escaparate.

\section{Estudo Empírico}

Este traballo pretende realizar unha primera aproximación á importancia que ten o merchandising, e, en particular o deseño exterior do punto de venda, na xestión comercial das oficinas de farmacia como estratexia que contribúe a definir o posicionamento da empresa, aumentar o tráfico de clientes na sala de vendas e incrementar a venda de produtos de parafarmacia e EFP. Para iso, analizaremos diferentes aspectos relacionados co estado de conservación da fachada, os letreiros e a cruz identificativos da oficina de farmacia, a porta de entrada ao establecemento e o deseño do escaparate, e a súa influencia na venda libre.

\subsection{Formulación das hipóteses}

Como comentouse anteriormente o obxectivo principal que se pretende con esta investigación é analizar a relación existente entre o deseño exterior da oficina de farmacia e a venda libre.

O deseño exterior do punto de venda ten unha importancia crucial na imaxe comercial que a farmacia quere transmitir e na atracción dos clientes potenciais ao establecemento comercial. Ademais, contribúe a captar a atención dos clientes potenciais e indúceos a entrar no establecemento comercial incrementando a posibilidade de que merquen produtos incluídos no conxunto de produtos da empresa (Martínez, 2005; Díez, Landa e Navarro, 2006; Siles, 2012).

Por outra banda, hai que ter en conta que na actualidade as farmacias dependen cada vez máis da venda libre e non tanto da venda de medicamentos con receita, polo que é fundamental que a través do deseño e implantación da súa estratexia comercial, consigan captar a atención dos seus clientes potenciais co obxectivo de que entren no establecemento comercial e así poder incrementar a venda de produtos de parafarmacia e EFP. Neste sento, propóñense as seguintes hipóteses de investigación:

$\mathbf{H}_{1}$ : Existe unha relación positiva entre o estado de conservación do exterior da farmacia e a venda libre da farmacia.

$\mathbf{H}_{2}$ : Existe unha relación positiva entre a visibilidade da farmacia para os viandantes e a venda libre da farmacia.

$\mathbf{H}_{3}$ : Existe unha relación positiva entre o deseño do escaparate e a venda libre da farmacia.

$\mathbf{H}_{4}$ : Existe unha relación positiva entre a utilización de portas automáticas e transparentes e a venda libre da farmacia.

\subsection{Medida das variables}




\subsubsection{Instrumento de medida do deseño exterior do punto de venda}

Nesta investigación analizáronse cinco elementos que configuran o deseño exterior da farmacia: a fachada, os letreiros exteriores, a cruz, a porta de entrada e o escaparate.

Para analizar o estado de conservación da fachada, os elementos identificativos da farmacia (os letreiros e a cruz) e a porta de acceso á farmacia, formulouse unha serie de preguntas respondidas polos visitadores de farmacia ${ }^{2}$, empregando unha escala de Likert de 1 a 5, (1=Moi malo e 5=Moi bo).

Táboa 1: Escala de medida da conservación e visibilidade da fachada e da porta de entrada

Estado de conservación da fachada.

Estado de conservación da cruz.

Estado de conservación do letreiro identificativo da farmacia.

Visibilidade da cruz para os viandantes situados a unha certa distancia da farmacia.

Visibilidade do letreiro identificativo para os viandantes situados a unha certa distancia da farmacia.

\begin{tabular}{|l|c|}
\hline A porta de acceso á farmacia é transparente. & ? $\mathrm{SI}^{\text {NON }}$ \\
\hline A porta de acceso á farmacia é de abertura automática. & [ $\mathrm{SI}$ \\
& $\mathrm{NON}$ \\
\hline
\end{tabular}

Para analizar o tipo de portas utilizadas polas oficinas de farmacia fixéronse dúas preguntas dicotómicas. Tamén foron respondidas polos visitadores de farmacia.

Táboa 2. Tipos de portas das farmacias

A porta de acceso á farmacia é transparente.

A porta de acceso á farmacia é de abertura automática.

\begin{tabular}{|c|c|} 
? SI ? \\
NON \\
\hline automática. \\
NON \\
\hline
\end{tabular}

Tendo en conta a crecente importancia que o deseño do escaparate representa para as oficinas de farmacia como ferramenta de comunicación do conxunto de produtos que se ofrece aos clientes en potencia, formulouse unha serie de preguntas respondidas polos visitadores de farmacia, agás a última que foi respondida polos titulares da oficina de farmacia, empregando unha escala de Likert de 1 a 5 , (1=Totalmente en desacordo e $5=$ Totalmente de acordo).

\section{Táboa 3: Escala de medida do escaparate}

A decoración do escaparate é axeitada á época do ano.

Os escaparates están correctamente iluminados.

O escaparate está ordenado.

Utilízanse elementos decorativos para mellorar a visibilidade do escaparate como displays, mobles decorativos...

Son facilmente identificables os prezos dos produtos situados no escaparate.

Está planificada a frecuencia de cambio dos escaparates da farmacia

2 Como exporase a continuación, a enquisa foi cuberta por 5 visitadores da empresa COFARES e polos farmacéuticos titulares das oficina de farmacia. 
Ademais, para describir mellor o perfil das oficinas de farmacia en relación co deseño exterior do punto de venda, fixéronse as seguintes preguntas respondidas polos visitadores de farmacia:

\section{Táboa 4: Dispoñibilidade do logotipo e directorio de servizos, e letreiro} identificativo iluminado

\begin{tabular}{|l|l|}
\hline A farmacia ten un logotipo que a identifica. & @SI $\quad$ NON \\
\hline Na fachada expónse un directorio cos servizos que ofrece a farmacia. & @SI $\quad$ NON \\
\hline Oletreiro identificativo da farmacia está iluminado. & @ SI $\quad$ NON \\
\hline
\end{tabular}

\subsubsection{Instrumento de medida da venda libre na oficina de farmacia}

Esta pregunta foi respondida polo titular da oficina de farmacia e categorizouse da seguinte forma.

\section{Táboa 5: Escala de medida da venda libre na farmacia}

\begin{tabular}{|l|}
\hline $\begin{array}{l}\text { Indique cal é o volume de vendas obtido pola súa farmacia de produtos de } \\
\text { parafarmacia e EFP no derradeiro ano: }\end{array}$ \\
\hline Menos de 150.000 euros. \\
\hline Entre 150.001 e 300.000 euros. \\
\hline Máis de 300.000 euros. \\
\hline
\end{tabular}

\subsubsection{Escala de medida dos conceptos latentes}

Tendo en conta a natureza exploratoria da presente investigación, creáronse tres novas variables de carácter latente. E dicir, que non se poden observar de forma directa e que a súa medición se realiza a través de variables observadas ou manifestas.

Para a creación destas variables latentes ou construtos ${ }^{3}$ seguimos a recomendación de Bollen (1989) que considera necesario xerar unha batería de ítems ou indicadores, baseándose na teoría previa, a través da que se representarán as diferentes variables latentes.

Estas variables son de natureza reflectiva, é dicir, as variables latentes observables son expresadas en función do construto (Bollen, 1989). A súa característica chave é que un cambio na variable latente se verá reflectido nun cambio en todos os indicadores (Bollen e Lennox, 1991). Polo tanto, as variables manifestas ou observables son as variables dependentes, namentres que a variable latente é a independente (Diamantopoulos, 1999). As medidas dun construto reflectivo deberían estar correlacionadas e acadar unha alta consistencia interna (elevado valor do Alpha de Cronbach) (Roldán, 2000).

Considérase que o valor mínimo que debe ter o Alpha de Cronbach é 0,7 . Porén, se o obxectivo do estudo é de carácter confirmatorio non se deberían aceptar valores inferiores a 0,8 (Luque, 1997).

${ }^{3}$ Hair, Bush e Ortinau (2004), definen construto como a variable hipotética formada por un conxunto de respostas ou comportamentos compoñentes que se consideran que están relacionados. 
A continuación, procédese ao cálculo deste coeficiente para todas as variables latentes creadas. Como pódese observar na seguinte táboa, a consistencia interna dos construtos, avaliada a través do $\alpha$ de Cronbach, é moi elevada, superando en todas as variables o valor de 0,8 recomendado para investigacións de carácter confirmatorio, cando esta investigación é de natureza exploratoria.

Táboa 6: Escala de medida e consistencia interna das variables latentes

\begin{tabular}{|l|r|}
\hline Variable & $\boldsymbol{\alpha}$ de Cronbach \\
\hline Estado de conservación do exterior da farmacia & $\mathbf{0 , 8 4 2}$ \\
\hline Estado de conservación da fachada & \\
\hline Estado de conservación da cruz & $\mathbf{0 , 8 0 1}$ \\
\hline Estado de conservación do letreiro identificativo da farmacia \\
\hline Visibilidade da farmacia para os viandantes \\
\hline Visibilidade da cruz para os viandantes situados a unha certa distancia da farmacia \\
\hline $\begin{array}{l}\text { Visibilidade do letreiro identificativo para os viandantes situados a unha certa distancia da } \\
\text { farmacia }\end{array}$ \\
\hline Deseño do escaparate \\
\hline A decoración do escaparate é axeitada para a época do ano \\
\hline Os escaparates están correctamente iluminados \\
\hline O escaparate está ordenado \\
\hline $\begin{array}{l}\text { Utilízanse elementos decorativos para mellorar a visibilidade do escaparate como displays, } \\
\text { mobles decorativos... }\end{array}$ \\
\hline Son facilmente identificables os prezos dos produtos situados no escaparate \\
\hline Está planificada a frecuencia de cambio dos escaparates da farmacia \\
\hline
\end{tabular}

\subsection{Definición da poboación e deseño da mostra}

A poboación obxecto de estudo da presente investigación, está constituída por todas as oficinas de farmacia con sede na Comunidade Autónoma de Galicia. Segundo o Consello Xeral de colexios oficiais de farmacéuticos en 2013 había en Galicia 1.345 oficinas de farmacia, as cales constitúen inicialmente a poboación obxecto de estudo.

A recollida e cumprimentación (só unha parte do cuestionario) dos datos, foi desenvolvida por cinco visitadores de farmacia da cooperativa farmacéutica COFARES (cooperativa farmacéutica española) nas súas delegacións de Galicia. As preguntas relacionadas coa facturación libre da farmacia e a frecuencia de cambio dos escaparates foron respondidas polo farmacéutico titular da oficina de farmacia.

Malia que COFARES é a empresa líder en distribución de medicamentos en España, non é provedora de todas as farmacias de España e de Galicia. Concretamente en Galicia hai 505 farmacias ás que subministran diferentes produtos relacionados co sector farmacéutico. Polo tanto, esta é a poboación obxecto do presente estudo, a cal representa o 37,55\% da totalidade das oficinas de farmacia existentes en Galicia. Cabe sinalar que non existe ningunha condición por parte da empresa para que calquera farmacia de Galicia entre a formar parte dos seus clientes. Polo tanto, pódese considerar que estas 505 farmacias representan perfectamente as diferentes tipoloxías de farmacias existentes en Galicia.

Desenvolvemos unha mostraxe non probabilística discrecional, xa que os elementos que formaron parte da mostra foron elixidos polo investigador e as persoas seleccionadas para a realización das enquisas. A mostra quedou constituída por 234 farmacias que responderon ao cuestionario presentado. Isto significa que se entrevistou ao 46,34\% da poboación obxecto de estudo e ao $17,40 \%$ das farmacias galegas.

A recollida dos datos realizouse durante os meses de marzo e abril de 2014. 
Unha vez analizados os cuestionarios recibidos, detectouse que 53 farmacias non contestaron á pregunta relacionada coas vendas obtidas no último ano en produtos de parafarmacia e EFP.

Este problema tívose en conta cando se realizou a análise dos datos. Neste senso, para todas as análises descritivas realizadas consideráronse a totalidade dos cuestionarios obtidos, é dicir, 234 farmacias, namentres que para a verificación das hipóteses formuladas utilizáronse 181 cuestionarios.

\subsection{Procedemento e técnicas de análise dos datos}

Para o tratamento dos datos utilizouse o paquete estatístico SPSS 20.0 para Windows.

Para realizar as análises descritivas das variables calculáronse as frecuencias e as medias das variables incluídas na investigación.

Para contrastar as hipóteses, tendo en conta as características das variables (as latentes son variables continuas e a venda libre é unha variable categórica ordenada), utilizouse unha regresión loxística ordenada que nos permite comprobar se existe relación entre as variables e se esta relación é positiva ou negativa. Tamén se utilizou a proba chi-cadrado para analizar a relación entre a porta de entrada e a venda libre.

\subsection{Estudo descritivo da mostra}

Neste apartado expoñeremos as características descritivas máis significativas da mostra, co obxectivo de establecer o perfil tipo das farmacias de Galicia en relación co deseño exterior do punto de venda.

No seguinte gráfico recóllense as puntuacións medias obtidas no estudo en relación co nivel de conservación de tres elementos integrantes do deseño exterior do punto de venda: a fachada, a cruz e o letreiro identificativo da farmacia.

Como pódese observar, as puntuacións obtidas son moi semellantes nos tres aspectos analizados, arredor de 4 puntos, o que indica que os farmacéuticos se preocupan por coidar o aspecto exterior do seu local comercial. Aínda que, debido á importancia que teñen estes tres aspectos sobre a imaxe que proxectan aos seus clientes, deben seguir investindo na súa conservación e mellorar a súa limpeza, iluminación...

Gráfico 1: Estado de conservación do exterior da oficina de farmacia

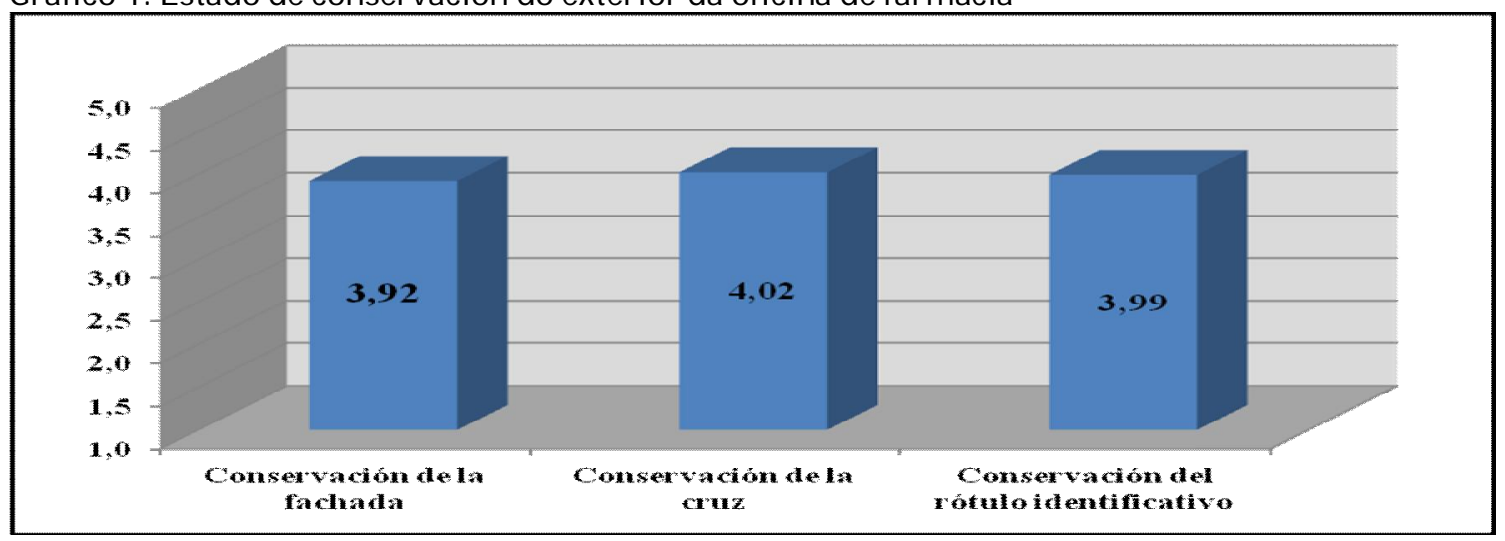

Outro aspecto analizado está relacionado coa visibilidade por parte dos potenciais clientes dos elementos identificativos da farmacia, o letreiro e a cruz. Como pódese observar no seguinte gráfico, a puntuación media obtida en ámbolos dous casos é similar á obtida no estado de conservación deses dous elementos, aínda que un poco inferior en relación coa visibilidade do letreiro identificativo (3,99 fronte a 3,80). Neste senso, os farmacéuticos deberían procurar mellorar o deseño e colocación na fachada dos letreiros identificativos da farmacia. 
En relación coa cruz, hai determinados aspectos que non se poden modificar, como é o tamaño, pero dentro das diferentes tipoloxías de cruces existentes, débese seleccionar a que resulte máis atractiva.

Gráfico 2: Visibilidade dos elementos identificativos da oficina de farmacia

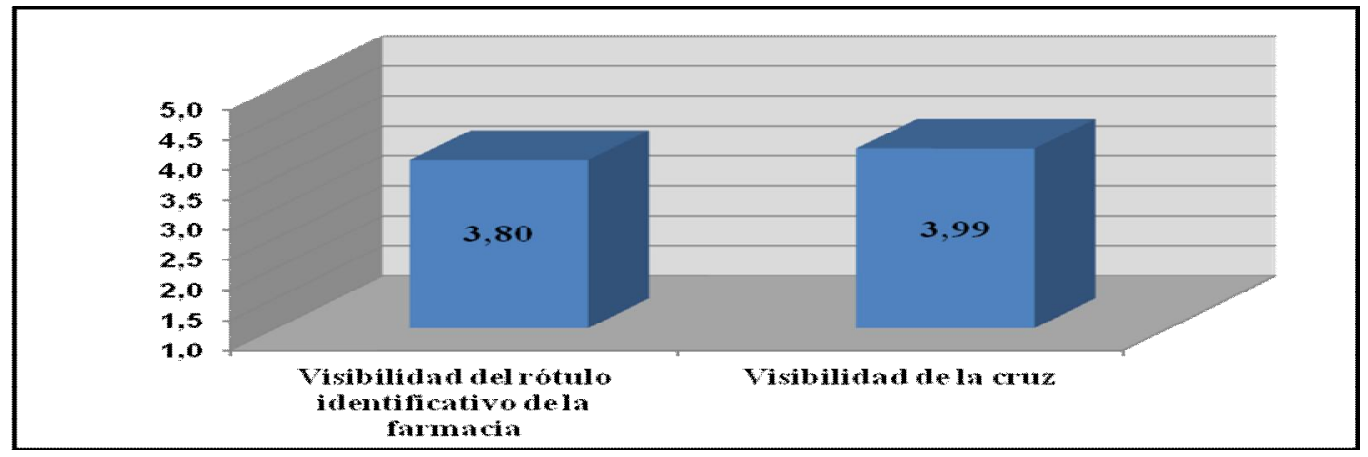

A porta de entrada dunha oficina de farmacia debe facilitar o acceso á sala de vendas de tal xeito que non sexa unha barreira e convide a entrar aos clientes. As investigacións consultadas coinciden en indicar a necesidade de portas de entrada transparentes que permitan observar o interior da farmacia e con abertura automática que facilite a entrada. Os resultados obtidos nesta investigación revelan que a meirande parte das farmacias consultadas dispoñen dunha porta de acceso transparente $(77,80 \%)$, pero soamente 0 $58,10 \%$ dispón de portas de abertura automática. Polo tanto, as farmacias de Galicia deben mellorar estes dous aspectos coa finalidade de facilitar o acceso aos clientes e a visibilidade da sala de vendas.

Táboa 7: Porta de acceso á oficina de farmacia

\begin{tabular}{|l|c|c|}
\hline Características da porta de acceso á farmacia & \multicolumn{1}{c|}{ Si } & \multicolumn{1}{c|}{ Non } \\
\hline A porta de acceso á farmacia é transparente & $77,80 \%$ & $22,20 \%$ \\
\hline A porta de acceso á farmacia é de abertura automática & $58,10 \%$ & $41,90 \%$ \\
\hline
\end{tabular}

En relación co escaparte, a característica peor valorada obténse en que é difícil identificar os prezos dos produtos alí expostos $(2,66)$. O farmacéutico titular débelle outorgar máis importancia a este aspecto, porque é unha das variables que máis inflúen no proceso de decisión de compra dos consumidores e, polo tanto, é necesario proporcionarlles esa información, onde moitas veces se sorprenden polos prezos económicos da farmacia fronte a outros competidores.

Un aspecto que tamén se debe resaltar, é que a puntuación media obtida en relación coa planificación da frecuencia de cambio dos escaparates non é moi elevada $(3,28)$, o que significa que os titulares da oficina de farmacia non lle conceden na actualidade demasiada relevancia á función que estes desempeñan como elemento de comunicación do establecemento comercial. Debemos recordar que esta pregunta foi respondida polo propietario da oficina de farmacia. As puntuacións medias máis elevadas obtéñense en que o escaparate está ordenado $(3,71)$ e que a decoración é axeitada para a época do ano na que nos atopamos $(3,70)$. 
Gráfico 3: Valoración do escaparate da oficina de farmacia

Está planificada a frecuencia de cambio do escaparSertes1

O escaparate está ordenado

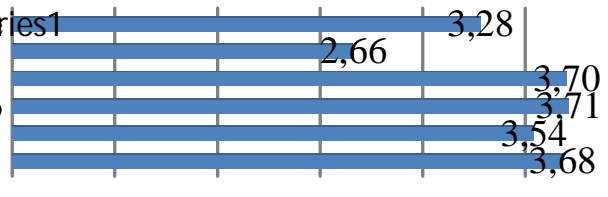

$1,0 \quad 1,5 \quad 2,0 \quad 2,5 \quad 3,0 \quad 3,5 \quad 4,0$

En relacionado coa imaxe personalizada da oficina de farmacia, comprobamos que soamente o 31\% creara o seu propio logotipo, ademais do oficial co que contan a meirande parte delas.

Por outra banda, constatouse que moitas das farmacias analizadas non dispón dun directorio cos servizos que ofrecen (59\%). Posiblemente sexa debido a que son moi poucas as farmacias que proporcionan servizos adicionais aos seus clientes, ademais dos correspondentes á dispensación de medicamentos e produtos de parafarmacia e EFP. Porén, cando a farmacia incremente a súa oferta de servizos profesionais farmacéuticos, debe comunicarllo aos seus clientes, e unha forma de facelo é a través dun directorio de servizos. Este tipo de servizos son difíciles de facer rendibles por si sós pero poden outorgar un valor diferencial á farmacia e facilitar a fidelización dos clientes.

En relación co letreiro identificativo do punto de venda, constatouse que só nun $55 \%$ das farmacias analizadas estaba iluminado. Considerando que este é un instrumento moi importante como sinal de identidade e atracción ao punto de venda, as farmacias deberían mellorar substancialmente a súa visibilidade mediante a súa iluminación.

Finalmente, como expúxose anteriormente, das 234 farmacias que participaron na enquisa, 181 responderon á pregunta relacionada coas vendas obtidas no último ano en produtos de venda libre.

Os resultados obtidos recóllense na seguinte táboa. Como pódese observar a meirande parte das farmacias de Galicia teñen unha facturación en venda libre inferior a 300.000 euros $(75,20 \%)$. Os cambios que se produciron no sector dos medicamentos en España nos últimos anos deberían provocar un cambio de xestión das farmacias que permitan compensar a redución de ingresos proporcionados polos medicamentos con receita con este tipo de produtos.

Táboa 8: Volume de vendas de produtos de parafarmacia e EFP

\begin{tabular}{|l|r|}
\hline \multicolumn{1}{|c|}{$\begin{array}{c}\text { Volume de vendas obtido pola farmacia en produtos de } \\
\text { parafarmacia e EFP no último ano }\end{array}$} & Porcentaxe \\
\hline Menos de 150.000 euros & $38,70 \%$ \\
\hline Entre 150.001 e 300.000 euros & $36,50 \%$ \\
\hline Máis de 300.000 euros & $24,80 \%$ \\
\hline
\end{tabular}

\subsection{Resultados da investigación}

A continuación procédese á análise das hipóteses formuladas.

No caso da análise da relación entre variables latentes e a venda libre, debemos indicar que os coeficientes obtidos da análise de regresión loxística ordenada indican a 
probabilidade logarítimica ordenada para un aumento dunha unidade na puntuación da variable dependente, é dicir, aumenta unha unidade a puntuación media de cada variable, o coeficiente indica a probabilidade de que a venda libre pase a estar nunha categoría superior.

\subsubsection{Relación entre o estado de conservación do exterior da farmacia e a venda libre}

A análise efectuada amosa a existencia dunha relación significativa $(\mathrm{p}=0,022)$ e positiva (coeficiente $=0,393$ ) entre o estado de conservación da fachada e a venda libre na farmacia. Como sinala González (2012), o exterior da farmacia debe estar limpo e en bo estado de conservación, xa que é o primeiro contacto que os clientes teñen co punto de venda, utilizándose tamén como elemento de atracción, animación e promoción co fin de xerar dinamismo e mobilidade (González, 2008b). Ademais, constitúe unha fonte de información que xera unha primeira impresión que inflúe directamente na decisión de entrar ou non no establecemento comercial (Zorrilla, 2002).

Polo tanto, isto é un primeiro paso para que o cliente acceda á farmacia, o cal inflúe directamente na posibilidade de que se incrementen as vendas, xa que se presupón que a maior número de clientes que entren, máis posibilidades hai que adquiran os produtos que necesitan.

\subsubsection{Relación entre a visibilidade da farmacia para os viandantes e a venda libre}

A análise efectuada amosa a existencia dunha relación significativa $(p=0,000)$ e positiva ( coeficiente $=0,556$ ) entre a visibilidade da farmacia para os viandantes e a venda libre da farmacia.

O letreiro e a cruz son elementos fundamentais de identificación, comunicación e diferenciación da farmacia. Canto máis visibles sexan, máis posibilidades existen que esta sexa percibida a unha certa distancia polos viandantes.

A maior visibilidade da farmacia facilita unha fácil localización polos clientes potenciais, e na mesma dirección que expuxemos anteriormente, influírá positivamente na posibilidade de que entren no punto de venda e, polo tanto, increméntense as vendas da oficina de farmacia.

\subsubsection{Relación entre o deseño do escaparate e a venda libre da farmacia}

A análise efectuada amosa a existencia dunha relación significativa $(p=0,000)$ e positiva (coeficiente $=0,645$ ) entre o deseño do escaparate e a venda libre da farmacia.

A pesar de que o escaparte dunha oficina de farmacia non ten a mesma relevancia que para outros formatos comerciais minoristas, os resultados desta investigación confirman o resultado doutras investigacións no senso de que o escaparate é un importante instrumento de comunicación que transmite información sobre o conxunto de produtos do establecemento comercial, actuando como un elemento de persuasión cara 0 consumidor e de animación do punto de venda.

Polo tanto, como sinala García (2008), o escaparate dunha oficina de farmacia, se consegue espertar atención e interese, provocará moitas compras impulsivas e será un instrumento moi valioso de promoción do negocio.

\subsubsection{Relación entre as portas de entrada e a venda libre}

Para analizar a influencia das portas de entrada na venda libre das oficinas de farmacia utilizouse a proba chi-cadrado. Neste senso, atopouse unha relación significativa e positiva entre as farmacias que posúen unha porta de acceso transparente e a venda libre $(p=0,004)$. Tamén se atopou unha relación significativa e positiva entre as farmacias cuxa porta de acceso é de abertura automática e a venda libre $(p=0,000)$.

Como pódese observar na seguinte táboa, o 68,1\% das farmacias que teñen a porta de acceso transparente teñen unha facturación en produtos de parafarmacia e EFP superior a 
150.000 euros. Nesta mesma dirección, o 76,2\% das farmacias que teñen a porta de acceso automática teñen unha venda libre superior a 150.000 euros.

Estes resultados amosan que é importante para as farmacias a instalación de portas automáticas transparentes, xa permiten unha mayor accesibilidade ao punto de venda e estimulan ao cliente a entrar no establecemento comercial.

Táboa 9: Relación entre as portas de acceso á farmacia e a venda libre

\begin{tabular}{|l|c|r|r|r|r|}
\hline \multirow{2}{*}{$\mathbf{X}^{2}(\boldsymbol{\alpha}=\mathbf{0 , 0 5})$} & $\begin{array}{l}\text { P=0 } \\
\mathbf{0 0 4}\end{array}$ & \multicolumn{4}{|c|}{ Venda libre da farmacia } \\
\cline { 3 - 6 } & $\begin{array}{c}\mathbf{P = 0} \\
\mathbf{0 0 0}\end{array}$ & $\begin{array}{c}\text { Menos de } \\
\mathbf{1 5 0 . 0 0 0 €}\end{array}$ & $\begin{array}{c}\text { Entre 150.001€ } \\
\mathbf{e ~ 3 0 0 . 0 0 0 €}\end{array}$ & $\begin{array}{c}\text { Máis de } \\
\mathbf{3 0 0 . 0 0 0 €}\end{array}$ & Total \\
\hline \multirow{2}{*}{$\begin{array}{l}\text { A porta de acceso á farmacia é } \\
\text { transparente }\end{array}$} & $\mathrm{Non}$ & $60,5 \%$ & $23,3 \%$ & $16,2 \%$ & $100 \%$ \\
\cline { 2 - 6 } & $\mathrm{Si}$ & $31,9 \%$ & $40,6 \%$ & $27,5 \%$ & $100 \%$ \\
\hline \multirow{2}{*}{$\begin{array}{l}\text { A porta de acceso á farmacia é de } \\
\text { abertura automática }\end{array}$} & $\mathrm{Non}$ & $57,5 \%$ & $30,0 \%$ & $12,5 \%$ & $100 \%$ \\
\cline { 2 - 6 } & $\mathrm{Si}$ & $23,8 \%$ & $41,6 \%$ & $34,6 \%$ & $100 \%$ \\
\hline
\end{tabular}

\section{Discusión e implicacións para a xestión}

\subsection{Conclusións}

Os considerables cambios lexislativos que se desenvolveron en España nos últimos anos no sector da oficina de farmacia, supuxeron unha redución considerable da súa marxe operativa, polo que se ve obrigada a compensar a caída de ingresos obtidos na venda de medicamentos por prescrición facultativa, co aumento na facturación de produtos de parafarmacia e especialidades farmacéuticas publicitarias. Para conseguir este obxectivo é moi importante crear un deseño exterior do punto de venda atractivo para captar a atención dos clientes, incitar a entrada no establecemento comercial e provocar accións de compra.

Neste senso, nesta investigación demostrouse que:

O estado de conservación do exterior da farmacia (fachada, cruz e letreiro identificativo) constitúe un determinante esencial da venda libre. Neste senso, é importante que as farmacias se preocupen constantemente por manter un aspecto coidado e atractivo dos elementos exteriores do local comercial.

As farmacias que teñen unha maior visibilidade a través da colocación e o deseño da cruz e o letreiro identificativo, obteñen unhas maiores vendas de produtos de parafarmacia e EFP. Dentro das limitacións legais impostas por cada Comunidade Autónoma en relación coa cruz, as farmacias deben preocuparse de elixir un deseño atractivo e de mantela nun bo estado de conservación. O mesmo débese sinalar para os letreiros identificativos, malia que neste caso o farmacéutico titular dispón dunha maior liberdade no seu deseño.

Verifícase, malia que ata a actualidade as farmacias non prestaron moita atención ao deseño dos escaparates, que este teñen unha gran influencia na venda libre. Por iso, deben adicar máis recursos e atención aos escaparates, co obxectivo de captar a atención dos viandantes.

Finalmente, amosouse que as farmacias que teñen portas de entrada transparentes e de abertura automática obteñen unha maior facturación en produtos de venda libre.

\subsection{Implicacións para a xestión}

O desenvolvemento da venda libre da oficina de farmacia é un reflexo da actitude positiva e proactiva do farmacéutico titular, que se debe manifestar na súa predisposición para 
asignar recursos económicos e materiais co obxectivo de mellorar a xestión comercial do seu negocio. Para iso, é necesaria unha grande implicación por parte do farmacéutico, cunha mente aberta fronte aos novos cambios e unha actitude positiva para acometer as transformacións necesarias para diferenciarse dos seus competidores.

O farmacéutico titular debe asumir que está xestionando unha empresa, e, como tal, debe apostar pola aplicación das modernas técnicas comerciais que se están utilizando con éxito noutros establecementos minoristas, sen deixar de asumir o importante papel que debe desempeñar, tendo en conta o tipo de produtos que comercializa. É dicir, non se puede esperar, como tradicionalmente se adoitaba facer, a que o cliente entre pola porta a mercar medicamentos. Hai que atraer ao consumidor á farmacia e procurar que a experiencia de compra sexa positiva, fomentando a venda por pracer e a súa fidelidade á farmacia.

Neste senso, o deseño exterior do punto de venda xoga un papel fundamental na estratexia de posicionamento que o farmacéutico quere trasladar aos seus clientes, facilitando a visualización do establecemento e captando a atención dos consumidores para que entren e merquen os produtos que necesitan.

\subsection{Limitacións e futuras liñas de investigación}

Os resultados presentados neste traballo débense interpretar con prudencia, xa que esta investigación non está libre dunha serie de limitacións que se deben ter en conta á hora de avaliar e xeneralizar as conclusións obtidas. En todo caso, as limitacións sinaladas poden ser o xerme de futuras investigacións orientadas a mellorar o coñecemento sobre a aplicación do merchandising nas oficinas de farmacia e a súa influencia na rendibilidade do negocio.

En primeiro lugar, na mostra inclúese exclusivamente farmacias pertencentes á Comunidade Autónoma de Galicia, o cal dificulta a xeneralización dos resultados obtidos a outros ámbitos xeográficos.

O estudo foi realizado por cinco profesionais pertencentes ao equipo comercial de COFARES, e malia que se explicaron previamente as instrucións que deberían seguir para cubrir a parte do cuestionario que lles correspondía, somos conscientes de que as respostas ás preguntas medidas por unha escala de Likert podían variar dun suxeito a outro debido á diferente percepción que poida ter cada participante perante un mesmo feito ou cuestión.

Para a elaboración do cuestionario non dispoñiamos doutros estudos semellantes que puidésemos utilizar como referencia para a elaboración das preguntas, polo que recorremos fundamentalmente aos estudos teóricos recollidos neste traballo e á experiencia dos investigadores. Malia a exhaustiva revisión realizada, somos conscientes da posibilidade de non contemplar todos os factores do deseño exterior do establecemento comercial que poidan condicionar a venda libre. Esta mesma formulación foi a que seguimos na elaboración das hipóteses e na creación das variables latentes.

Tendo en conta a natureza exploratoria desta investigación e, en relación coas variables latentes, soamente analizamos a fiabilidade do construto a través do Alpha de Cronbach. Porén, en investigacións de carácter confirmatorio serían necesarias outras análises relacionadas coa fiabilidade e validez das escalas de medida.

Finalmente, na investigación realizada faltan determinadas cuestións relacionadas coas técnicas de merchandising que se poderían ter incluído como: o ambiente do punto de venda, a xestión dos produtos, a actividade promocional, a orientación dos empregados cara os clientes, técnicas de animación do punto de venda, entre outras. 


\section{Bibliografía}

ARIAS, A. (2012): Gestión por categorías: cómo vender más cuando nadie compra. Madrid: Asun Arias, Consultores.

BOLLEN, K. (1989): Structural equations with latent variables, New York: John Wiley \& Sons, Inc.

BOLLEN, K.; LENNOX, R. (1991): “Conventional Wisdom on measurement: a structural equation perspective”, Psychological Paradigm, vol. 110 (2), pp. 305-314.

BROCAL, N.; VAILLO, M. (2005): Escaparatismo en la farmacia (en línea). Madrid: Correo farmacéutico de cuadernos de gestión, pp.15-26 (6 de abril de 2017).

http:// www.correofarmaceutico.com.

BROCAL, N.; VAILLO, M.; SERRANO, M.; GUILLÉN, J.; BARRIO, E. (2007): Cómo equipar la farmacia (en línea). Madrid: Correo farmacéutico de cuadernos de gestión, pp.15-26 (6 de abril de 2017). http:// www.correofarmaceutico.com.

CONSEJO GENERAL DE COLEGIOS OFICIALES DE FARMACÉUTICOS (2013): Farmacias accesibles para todos. Madrid: Consejo General de Colegios Oficiales de Farmacéuticos.

DE LA FUENTE, L. (2016): "Acuerdos win to win entre farmacia e industria", Farmacia profesional, vol. 30 (6), pp. 10-12.

DE LA FUENTE, L. (2017): “Situación y panorama de la farmacia 2016”, Farmacia profesional, vol. 31 (1), pp. 10-12.

DERMOACTIVA (2009): Gestión comercial. Potenciar promociones, animaciones y campañas, Madrid: Vichy y el Consejo General de Colegios Oficiales de Farmacéuticos.

DIAMANTOPOULOS, A. (1999): "Viewpoint. Export performance measurement: reflective versus formative indicators", International Marketing Review, vol. 16 (6), pp. 444-457.

DÍEZ, E. C.; LANDA, F. J. (1996): Merchandising: teoría y práctica. Madrid: Pirámide.

DÍEZ,E.C.;LANDA,F.j.;NAVARRO,A. (2006): Merchandising: teoría y práctica. 2ª ed. Madrid: Pirámide.

ESPAÑA. CONSELLERÍA DE SANIDAD (2008): Decreto 107/2008, de 15 de mayo, por el que se regula la señalización, información y publicidad de las oficinas de farmacia. Diario Oficial de Galicia, no105, de 2/ 06/2008.

ESPAÑA. MINISTERIO DE SANIDAD (1997): Ley 16/ 1997 de 25 de abril, de Regulación de Servicios de las Oficinas de Farmacia:" Módulos y distancias entre oficinas de farmacia. Boletín Oficial del Estado, nำ100, de 26/ 04/ 1997.

GARCÍA, J. (2008): “El escaparate”, Farmacia Profesional, vol. 22 (10), pp. 23-25.

GASULLA, A. (2008): "El escaparate: un gasto, una inversión o una fuente de ingresos", Aula de la farmacia: Revista profesional de formación continuada, vol. 4, (51), pp. 56-63.

GONZÁLEZ, A. (2005): Manual Práctico de Gestión de la Oficina de Farmacia. Nuevos enfoques, nuevos retos (Volumen I). Madrid: AMV Ediciones.

GONZÁLEZ, A. (2010): "Retail marketing (I): La oficina de farmacia como producto/ servicio orientado al cliente", Farmacia Profesional, vol. 24, (2), pp. 34-37.

GONZÁLEZ, A. (2012): Manual Práctico de Gestión de la Oficina de Farmacia. Gestión del día a día en tiempo de crisis (Volumen II). Madrid: AMV Ediciones.

GONZÁLEZ, M.A. (2008a):“El exterior del punto de venta”,Farmacia Profesional, vol. 22,(5), pp.32-34. GONZÁLEZ, M.A. (2008b): "Publicidad dinámica”, Farmacia Profesional, vol. 22, (11), pp. 16-18.

HAIR, J.F.; BUSH, R.P.; ORTINAU, D.J. (2004): Investigación de mercados, 2ª ed. México: McGraw-Hill. LUQUE, T. (1997): Investigación de marketing. Barcelona: Ariel.

MARTÍNEZ, I.J. (2005): La comunicación en el punto de venta. Estrategias de comunicación en el comercio real y online. Madrid: ESIC.

PALOMARES, R. (2009): Merchandising. Teoría, Práctica y Estrategia. 2ª ed. Madrid: ESIC.

ROLDÁN, J.L. (2000): Sistemas de información ejecutivos (EIS): Génesis, implantación y repercusiones organizativas. Tesis Doctoral, Universidad de Sevilla.

SILES, A. M. (2012): "Estrategia de merchandising”, en S. Molinillo, S. (coord.): Distribución comercial aplicada, pp. 371-448. Madrid: ESIC.

ZORRILLA, P. (2002): "Nuevas tendencias en merchandising Generar experiencias para conquistar emociones y fidelizar clientes", Distribución y Consumo, nํ6, pp.13-20.

Revista Galega de Economía: http:// www.usc.es/ econo/RGE/ banvidag.htm 